\section{Critical success factors for Big Data adoption in the virtual retail: Magazine Luiza case study}

\author{
Bruno Muniz Félix \\ Elaine Tavares \\ Ney Wagner Freitas Cavalcante \\ Universidade Federal do Rio de Janeiro, Coppead Graduate S \\ chool of Business, Rio de Janeiro, Brazil
}

Received on

$11 / 12 / 2016$

Approved on

$09 / 12 / 2017$

Responsible editor:

Prof. Dr. Ignacio Canales

Evaluation process:

Double Blind Review

\begin{abstract}
Purpose - The objective of this research was to identify critical success factors for the adoption of Big Data in the virtual retail, through a case study of Magazine Luiza. The use of Big Data, in this case, focused on improving its system of recommendations for a better understanding of consumer behavior.
\end{abstract}

Design/methodology/approach - The case study was done through interviews, observation of the shopping recommendation system and analyzes of institutional presentations of the Bob project. A semistructured interview script was used in the interviews.

Findings - Based on the results, we outline some propositions related to the opportunities and obstacles for the implementation of Big Data in the virtual retail in Brazil. Some of these propositions are in line with what literature, especially BI, has been discussing. However, they still need to be discussed in the context of Big Data.

Originality/value - The main contribution of the research was the identification of relevant factors to the adoption of Big Data that were not considered as critical for the adoption of previous technologies.

Keywords - Big Data; Virtual retail; Case study; Magazine Luiza.

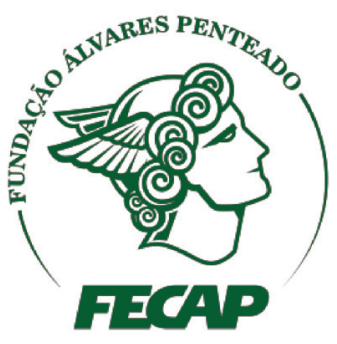

Review of Business Management

DOI: $10.7819 /$ rbgn.v20i1.3627 


\section{Introduction}

Technological development in the past decades increased significantly the volume of available data for organizations, impacting on decision making processes and results. Systems related to Big Data have acquired greater importance to business in recent years, as organizations face a bigger need to analyze abundant and diverse data (Chen, Chiang, \& Storey, 2012).

Expected benefits derived from the use of Big Data include integration of data from varied sources, the ability to capture and analyze substantial volume of structured and unstructured data, the enhancement of general analytical capabilities, analysis of information in real time, reduction of analysis and data processing costs, more transparency of information used in the decision making process, faster products and services customization, and the creation of new business models (Davenport, Barth, \& Bean, 2012).

Virtual retailing, for example, witnessed an exponential growth with the use of Big Data (Davenport, 2014). The reason behind this is that Big Data introduced techniques in this environment that allowed for a number of actions to be made to enhance the customer experience for those who access a website in search of a product. Moreover, it provided the companies with a greater ability to obtain and analyze consumer information (Davenport et al., 2012; McAfee \& Brynjolfsson, 2012).

Several studies focused on the understanding of critical success factors in the adoption of information systems, including Business Intelligence (BI) systems. Nevertheless, because Big Data systems are relatively new and academic literature still presents insufficient systematized knowledge on the topic, it becomes necessary to explore the critical success factors for the adoption of Big Data.

This study is, therefore, guided by the following research question: are the critical success factors for Big Data adoption the same factors that proved to be relevant for the adoption of previous data analysis systems, such as $\mathrm{BI}$ systems? As virtual retail is one of the main users of Big Data in the country (International Data Corporation [IDC], 2014; E-Bit, 2015), an exploratory investigation of the sector was conducted. The research's objective is to identify critical success factors for Big Data adoption by virtual retailers. More specifically, this research is based on the Magazine Luiza case study, a leading company regarding the use of Big Data tools with the purpose of better knowing its customers, optimizing customer loyalty, and generating financial revenue.

This article is organized as follows: first, we present the concept of Big Data and its benefits. We explore factors identified in the literature as potentially relevant for Big Data adoption. Next, we provide a description of the method applied and the case study. In the final considerations we summarize the propositions regarding the critical success factors for Big Data adoption by virtual retailers and point out suggestions for future research.

\section{Literature review}

\section{I Big Data and its benefits}

Big Data concerns datasets whose size is beyond the capacity of typical database software tools for capturing, storing, managing, and analyzing (Bruce, Lenita, \& Paul, 2013; Ohlhorst, 2013).

The main attributes related to the concept of Big Data are volume, speed and variety (Simon, 2013; Castro, 2014; Maçada \& Canari, 2014). Volume regards the increasing amount of data which directly impacts organizational processes and influence predictive and statistical methods. Variety concerns the ability to analyze an extensive and diverse range of data and sources, including structured, semi-structured and unstructured data (Ohlhorst, 2013). Finally, speed encompasses the ability for fast data analysis, often in real time (McAfee \& Brynjolfsson, 2012).

According to Novo and Neves (2013) and McAfee and Brynjolfsson (2012), the 
defining characteristics of Big Data are those that differentiate it from traditional BI systems. Big Data has a different approach: the process of storage and analysis is structurally modified so that it leads to the gathering and interaction of all data generated by an organization, enabling a subsequent decision on the use of such data (Ohlhorst, 2013).

From a managerial perspective, the organizations that benefit from Big Data focus on data flow as opposed to stocks - reflected in the processes of how they gain value from data - and they no longer manage based solely on historical data sets and start to put more emphasis on predictive models (Davenport, 2014).

The main benefits of Big Data for management are: (1) cost reduction and revenue increase; (2) enhancement of operational efficiency; (3) better decision making; (4) improvement of products and services (5) improvement in the innovation processes and development of new products and markets. (Leeflang, Verhoef, Dahlström, \& Freundt, 2014; Silva \& Campos, 2014; Minelli, Chambers, \& Dhiraj, 2013; Novo \& Neves, 2013; Ohlhorst, 2013).

\subsection{Relevant factors for Big Data adoption}

The adoption of Big Data faces challenges not yet properly covered in academic literature. Since this is a recent set of technologies, we reached for literature covering the managerial aspects of Big Data, as well as literature regarding information systems, especially BI systems. We chose this option because similarly to BI systems, technologies associated to Big Data aim the improvement of decision making process (Davenport, 2014; Yeoh \& Koronius, 2010). Second, because Big Data works as an umbrella for several technologies, methodologies and concepts of analysis that are not new, among them the vast majority of traditional BI systems (Ohlhorst, 2013). Finally, because the literature already noticed that some of the Big Data and data analysis projects success factors are similar to those regarding the adoption of BI systems (Davenport, 2014).

\subsection{Factors related to strategy, processes and leadership}

The adoption of a Big Data system may evolve into unpredictable paths (Yeoh \& Koronius, 2010). The strategy for Big Data adoption needs to be linked to the organizational strategy, and it also requires a decision on which analytical resources are needed and how they should be applied (Novo \& Neves, 2013). Priorities and problems to be solved must be defined, besides measurable standards (Minelli et al., 2013).

The engagement of the top management is important to gain the support and approval from executives to the endorsement of Big Data; the decision making based on analytics; and the identification of the major customers to comprise the data analysis (Novo \& Neves, 2013). It also facilitates access to the required operational resources, such as financing and professional skills, aside from its relevance for overcoming change barriers and for reformulation paradigms (Yeoh $\&$ Koronius, 2010).

\subsubsection{Factors related to human resources}

A challenge that Big Data may impose to organizations is the lack of professionals with the required skills and knowledge to deal with data analysis, something defined by Leeflang, Verhoef, Dahlström and Freundt, (2014) as talent gap. Several solutions have been proposed to address it, such as the investment in formal education and internal talent training. Talent retention is also a challenge, on account of market demand (Davenport, 2014).

\subsubsection{Relevant factors related to implementation management}

Some structures and functions are frequently found in IT implementations. Super user groups that engage in the implementation and later return to their original job functions is a well-known practice (Sumner, 1999; Somers, Nelson, \& Ragowsky, 2001).

There are two other aspects that should be highlighted regarding the implementation: the project management method and the use 
of a phased and evolutionary approach. Fast development methodologies are a better fit for larger data analytical applications if compared to conventional approaches. When fast approaches are used, minimum time is wasted in the prior identification of the system and more emphasis is placed on the quick delivery of smaller results. They also accommodate better quick changes in the development plans, having a superior performance in scenarios of uncertainty (Davenport, 2014). The use of a phased approach is viewed as a critical success factor in the adoption of information systems. Splitting the project into phases, through a gradual execution, facilitates the implementation (Gupta, Gupta, \& Singhal, 2014).

\subsubsection{Factors related to ethics and privacy}

Big Data raises unsettling issues regarding ethics, such as what data should be used in an analysis (George, Hass, \& Pentland, 2014). Users are not necessarily aware of all the gains derived from information they have posted. It is necessary to debate when and which data may be used in the Big Data strategy given that the difficulty to ensure data safety and privacy can make the project infeasible (Wigan \& Clarke, 2013). It is crucial to have a constant ethical questioning not only regarding the use, but also the data collection, the storage and access control (Simon, 2013).

Privacy is among Big Data's main concerns. It refers to information personally identifiable (PII), i.e., information that may be used to identify an individual. The issue of anonymity has raised several debates. Minelli, Chambers and Dhiraj (2013) believe that data collected for a specific purpose can become anonymous and later used for other purposes, such as the identification of collective patterns. The challenge is that the more anonymous the data, the less useful it becomes.

\section{Methodological procedures}

\section{I Case study: Magazine Luiza}

Magazine Luiza is one the major retail chains focused on durable goods and is widely present among Brazilian popular social classes. It holds a base of 36 million registered customers, $30 \%$ of them still active. The group is comprised of 736 stores, more than 24 thousand employees, 8 Distribution Centers, and operates in 16 Brazilian states, which accounts for $75 \%$ of the national GDP. The company has a platform of multichannel retail, integrating the teams of E-commerce Marketing and physical stores Marketing (Magazine Luiza, 2016).

Innovation is a routine practice at Magazine Luiza. In 1992, for example, the company was the country's pioneer in the development of online stores - in-store multimedia terminals where customers could purchase products not displayed at the physical store with the assistance of a salesperson. Nowadays, E-commerce is completely integrated at Magazine Luiza and it offers a range of products of approximately 44 thousand items. With the release of "Magazine Você" in 2011, with more than 60 thousand stores in its first year, the company developed the first initiative of social commerce in Brazil (Magazine Luiza, 2016).

In 2014, Magazine Luiza created "Luizalabs" - a Technology and Innovation lab at the Research and Development Center - with the objective of creating products and services with a focus on retail, offering more benefits and a better shopping experience for their customers. Comprised by a group of developers not dealing with the company's day-to-day operations and solely concerned with innovation, the lab holds a structure separated from Magazine Luiza. One of the main projects developed by Luizalabs is Bob, a Big Data application that changed the way of dealing with customized content at Magazine Luiza, leveraging sales and enhancing consumers' experience. Bob is currently responsible for all products recommendations from magazineluiza. com, also delivering shopping suggestions by e-mail and through display networks (Magazine Luiza, 2016). The implementation of Bob is the focus of this case study which aimed to identify opportunities and obstacles to Big Data adoption by virtual retailers in Brazil. 


\subsection{Data collection and analysis}

The case study was conducted through interviews, observation of the shopping recommendation system and analysis of project Bob's institutional presentations. Nine interviews were conducted with Magazine Luiza's IT team members, including members of Luizalabs and major internal clients, users of Big Data analyses developed by Luizalabs. Interviews were conducted using a semi-structured interview script (Appendix 1). As previously mentioned in the Literature Review, there are limited publications on critical success factors for Big Data implementation, therefore the script was also based on critical factors for BI systems implementation.

Interviews were recorded with the participants' consent and they were informed that identities would remain confidential. A list with the participants' job titles is presented in Table 1 where interviewees were grouped by job function.

Table 1

\section{Participants}

\begin{tabular}{ll}
\hline Interviewees & Job Titles \\
\hline I1, I2 and I3 & IT and CTO Managers \\
I4 and I5 & E-commerce marketing analyst and CRM and Marketing Intelligence Manager \\
I6, I7, I8 and I9 & Big Data Development leader, Junior Developer and Big Data Researcher. \\
\hline
\end{tabular}

Data was collected through content analysis technique. The categories presented were defined a priori and a posteriori, i.e., they were created according to the bibliography review and later complemented as new information would show an opportunity or a challenge for the use of Big Data by virtual retailers. A list of potentially relevant factors for the adoption and use of Big Data technologies was created based on the literature review, which by no means intended to be in-depth given the exploratory nature of the study (Table 2).

Table 2

\section{Relevant factors for the adoption of BI technologies and Big Data}

\begin{tabular}{|c|c|}
\hline Category & Source \\
\hline Strategic alignment & Yeoh and Koronius, 2010; Novo and Neves, 2013; Minelli et al., 2013. \\
\hline Top management involvement & Yeoh and Koronius, 2010; Novo and Neves, 2013; Davenport, 2014. \\
\hline Compatibility with organizational processes & $\begin{array}{l}\text { Yeoh and Koronius, 2010; Ohlhorst, 2013; Novo and Neves, 2013; Kim, Trimi and } \\
\text { Chung, 2014. }\end{array}$ \\
\hline Information sharing & Yeoh and Koronius, 2010; Ohlhorst, 2013; Novo and Neves, 2013; Kim et al., 2014. \\
\hline $\begin{array}{l}\text { Cultural change for data orientation and } \\
\text { experimentation }\end{array}$ & Schmarzo, 2013; Burton, Mastrangelo and Salvador, 2014. \\
\hline Overcoming the talent gap & Yeoh and Koronius, 2010; Davenport, 2014; Leeflang et al., 2014. \\
\hline Structure and functions for implementation & Sumner, 1999; Somers, Nelson and Ragowsky, 2001; Patterson, 2014. \\
\hline Communication & $\begin{array}{l}\text { Bingi, Sharma and Godla, 1999; Sumner, 1999; Somers et al., 2001; Ansarinejad, } \\
\text { Amalnick, Ghadamyari and Hatami-Shirkouhi, } 2011 .\end{array}$ \\
\hline Expectations management & Somers et al., 2001; Davenport, 2014. \\
\hline Agile methods & Ansarinejad et al., 2011 \\
\hline Privacy management & $\begin{array}{l}\text { Minelli et al., 2013; Simon, 2013; Wigan \& Clarke, 2013; George, Hass \& Pentland, } \\
2014 .\end{array}$ \\
\hline
\end{tabular}




\section{Presentation and data analysis}

\section{I The development of Bob and its benefits}

The use of analytics at Magazine Luiza derived from an initiative of the IT team responsible for E-commerce. Project Bob started with the development of Magazine Você:

The idea was to create a social commerce. We would take advantage of people's connections in social media, such as Facebook, and from there we would sell products (...) Later, when the project got online and because of the project's nature itself (open graph, which is a graph where you have vertices and angles connecting people to other people, interests, etc.), we started trying to connect this. (II)

The intention was to find out what people do at Magazine Você, to then suggest products to people in its networks. The behavior analysis made it possible to better understand the consumer behavior.

We had all our customers' data right here what they purchased, how much they paid for it, the payment method... Now with Big Data we have a larger volume of information so that we can infer more things. (I5)

\subsection{Strategic alignment}

The strategic impact of Big Data on Magazine Luiza is related to a better and faster understanding of the market to provide a guide for strategy. The possibility of customizing the experience to enhance the customer's satisfaction and increase loyalty is the main objective of Big Data use at Magazine Luiza.

Here there is the huge challenge of creating customer loyalty so that we may provide even more customized content for them. Our aim now is to improve this homepage so that it may have much more things to show you. (II)

\subsection{Top management involvement}

Bob's initiative originated from the technical area and gained support from the Executive Director. Project initiatives started to show up in the E-commerce area, later becoming Luizalabs, but the top management support was crucial for the project.

When the site started to perform better, the Executive Director liked how we worked. He said he had a project, Magazine Você, which he had been trying to develop for a long time but that he had not been able to conclude. I said it was possible to make it, but it needed to be done in totally another way, in terms of how the company considers technology. He agreed. (I1)

\subsection{Cultural change}

The use of Big Data at Magazine Luiza reflects the development of digital culture, where the work of the technological area is just one of its aspects. In the medium term, the organization strategy is focused on becoming a digital company.

Thinking about Magazine Luiza, I see how we are preparing a lot for what we call the digital transformation. The creation of Luizalabs represents this. (II)

The project went through a stage of changes in the organizational culture (Schmarzo, 2013; Burton, Mastrangelo, \& Salvador, 2014), which made it possible for the company to become data-oriented. These cultural changes were guided by the institution's fundamental values, such as respect for the customers.

We try to keep in mind that customers need to be satisfied with the experiences they will have with us, no matter the store. So, Big Data comes as a way of helping the customer to obtain this service. They become satisfied with the final experience. (I4) 
According to the facts presented, we outlined the following propositions:

P1: The alignment of Big Data projects with the organization strategy must favor its adoption. Changes in the organizational culture may favor the establishment of data orientation.

The alignment between Big Data projects and the organizational strategy is relevant for the adoption of Big Data because it identifies the needs to be satisfied and which capacities should be developed. Changes in the organizational culture may be necessary along the implementation of such projects, and a means to achieve the strategic objectives and create a dataoriented culture.

P2: The involvement of top management in the implementation and use of Big Data is important both to support and sponsor a new technology, as well as to help overcoming obstacles to change. The system being idealized by someone high in the hierarchy and/or counting on the support of the organization's top executives makes it possible to gain the necessary political support, providing the required autonomy for the analytics area, facilitating the necessary organizational changes, and the provision of resources and assistance to promote the solution internally.

\subsection{Alignment with the organizational processes}

The recommendation system started to be gradually expanded in order to gain insight into other areas and to develop new products. This expansion included the IT team in search for solutions that would eliminate restrictions presented by the business areas, changing the way things were done. Contrary to the literature, which points out that IT projects should look for an alignment with the organizational processes as a strategy to minimize resistance (Yeoh \& Koronius, 2010; Ohlhorst, 2013; Novo \& Neves, 2013; Kim, Trimi, \& Chung, 2014), the implementation of Big Data at Magazine Luiza was not restricted to these processes, as the goal was to improve performance.

We suggested personalizing the entire homepage for the customers. This is a paradigm shift in Brazil. A regular homepage had a conversion rate of $0.90 \%$ and ours had $12 \%$, with slots reaching up to $20 \%$ (...) Since Bob, we started to customize e-mails. (I1)

The cultural change needed to make the company data-oriented created resistance and demanded transformation processes.

The transformation process demanded changes in the data banks and new business processes. We questioned a lot the existing processes here, and this led us to gain this space (Luizalabs) now. (I3)

According to the abovementioned, we propose:

P3: Big Data projects that have the objective of fostering a digital culture should establish innovative processes, not necessarily aligned with the original processes.

The establishment of a data-oriented culture requires transformations in the institution's modus operandis and propositions of innovative business processes.

\subsection{Information sharing}

Resistance from the physical stores regarding online operations still exists and is negative as it hinders the gathering of useful data. This is not a matter of resistance to Big Data, but rather the perception that the virtual commerce 
represents a threat to the physical channel, in a retail company that used to operate through traditional sales channels.

Sometimes it is diffcult for a store manager to understand that his customer is more prepared than he is. He arrives at the store after having done considerable internet research for the purchase of an item. (I1)

The rupture of organizational silos so that more information sharing becomes possible is one of the greatest benefits of Big Data (Yeoh \& Koronius, 2010; Ohlhorst, 2013; Novo \& Neves, 2013; Kim et al., 2014). Pursuing congruence between the channels is a strategic alternative to overcome resistance. Moreover, information integration provided by Big Data is a way of integrating distribution channels, in alignment with the company's strategic objectives.

We have metrics, a percentage of people who go to the physical store, [but] before going to the store they check the products on the cell phone. What are we doing? When you get to the store, the salesperson will try to identify you - through your SSN, your e-mail, through something, and after they identify you, it will appear for them what you were searching on the website, what you probably were going to buy, which are the brands you are more interested in. And with Bob we have all this much easier. (I2)

The importance of building a data lake becomes clear in the interviews, even with the knowledge that the information extraction methods are still being understood.

I think that today not even the business area is clear about what they want, or how relevant certain data are for them. So, for now, we are gathering everything. But I believe that the volume won't be a problem because I think we don't have that much volume, if compared to what you see in other places. The way everything was structured here can hold much more than what we have now. (I3)

Transposing data from other systems to the data lake is a challenge. It is not possible to consolidate a large number of data bases into one data lake.

We have an ERP, two in fact, at the company. So, there are the commercial, financial ERP bases and I want to get the information they have there, from other very tiny systems, and I need to get all of this and take to the data lake. So, I take it there and transform it into a way that I may, by other paths, have access to the data and transform it into information that may be useful for something (I1).

We propose, therefore:

P4: The adoption of Big Data requires overcoming challenges related to information sharing between organizational silos.

Minimizing conflicts between distribution channels may improve information sharing. The development of a data lake favors the establishment of a data-sharing culture, despite the fact that it can be challenging to bring data from other systems. There are times when gathering all data into one data lake is not possible.

\subsection{Communication}

Communication, which is considered fundamental for the success of projects of this nature (Bingi, Sharma, \& Godla, 1999; Sumner, 1999; Somers et al., 2001; Ansarinejad, Amalnick, Ghadamyari, \& Hatami-Shirkouhi, 2011), allowed the IT area to show results and enabled the alignment between Big Data technical projects and business needs. 
The obstacles became easy to overcome with the results we were delivering. This started to get so large to the point that directors began to request for several functionalities or technologies for different business areas (e.g. store system). (I1)

Having gained trust, IT and business areas began to work in a more integrated manner.

On the website, we always used Bob a lot in partnership; the recommendations for the site were jointly made. So, the idea of Big Data began to develop and there was always someone from the site saying: "that's nice, it makes sense that we make it available for consumers with an algorithm rule so that they may understand or not the recommendations". (I4)

According to the abovementioned, we propose:

P5: Big Data projects conducted by technology areas should have an efficient communication for the promotion of the system, for its improvement and for conflict resolution. Communication enables IT and business areas to work in an integrated manner.

Communication enables the release of advanced analytical techniques results, favoring the acceptance of projects and the adoption of technologies, aiming for improvements, based on the understanding of users' needs, and helping with conflict resolution.

\subsection{Management of expectations and cultural experimentation}

It is also necessary to manage business area expectations given that demands for solutions have increased when the area noticed the value of Big Data. Users need to be shown what is possible and demands must be managed.
We always want more information, more data, and sometimes we don't have the structure we would like to have. So sometimes we want something we have not yet achieved, but it's a matter of priorities. So, we prioritize what is more important, what is going to bring more results and we negotiate deadlines. We don't have a problem with that. (I5)

This last statement makes it clear that the experimentation issue coexists within the technical and business areas.

I'm not saying that all decisions need to be made based only on what we are seeing in the data. There are things that you will want to test and see what is going to happen. You need to be able to balance this. (I1)

That said, we propose:

P6: It is necessary to manage users' expectations regarding Big Data projects in order to prioritize demands and show possibilities to the users.

As results begin to show up and trust in the technical area builds up, the demand and expectations for projects increase and must be managed.

P7: The establishment of a digital culture - data-oriented - coexists with a culture of experimentation.

The technical area is not the only one to experiment solutions, but the business area as well will make some decisions not solely based on data, as a means to experiment new ideas.

\subsection{Organizational structure}

Another condition that favored the development of Big Data was the review of the organizational structure, mainly in the IT area, in order to adjust and expand it. 
As results started to show up, a new area called Luizalabs was created and brought together analytics activities. This new area works in an integrated way with business areas (EI). We started to grow to the point we would become a separate company, only for Research and Development.

It also became clear that developers don't have direct contact with users, as a shield strategy from day-to-day problems and priority pressures.

The communication is made through the IT manager. This approach is interesting. It has a lot to do with Scrum methodology, which shields us from external problems. A big problem we see, mainly in other areas, is getting one million requests from one million different people and all being high priority. (I9)

Regarding the organizational structure, we propose:

P8: Reviewing the organizational structure may be favorable for the development of a digital culture.

Reviewing the organizational structure may be favorable for the development of a digital culture as it adjusts and expands analytics capacity. Digital companies tend to have analytics disseminated throughout the business areas and not exclusively centered in IT. This dissemination results from the maturity of analytics in the organization.

\section{Io Agile method}

Projects are mainly developed using the agile method and the development team has also a good deal of autonomy in the IT area.

We work with Scrum, but in our own way. Scrum is super complete, but our team is small and doesn't need to have everything. We have sprints, we make planning poker. We have a very precise planning and later, after having set the Sprint, we don't add anything else. If we add, we document it: this change was made. So, we had a bad planning and will make it better for the next one. (I2)

The team developing the analytics values this autonomy and considers the success of their projects as a major reward for their work.

The greatest reward we get is seeing what we create make money for the company in a way we consider legal. We are not pushing anything; we don't do anything that we consider unethical. We gave a lecture at Amazon about recommendation. That's a reward. (I2)

The use of open source technology is a mark of Big Data projects.

Here we work a lot with open source technologies. In fact, only with it. And it's not even because it's a company decision to save money... it's because we believe that it really is better. And we don't have anything limited to one single language. (I2)

\section{P9: Agile project development methods are more adequate for Big Data.}

Given that agile project development methods have more flexibility for scope definition and require less user involvement, they seem more adequate for Big Data projects that target the development of an experimental culture. Gradual and more rapidly verifiable results build users' trust, and should facilitate the required changes in the organizational culture. These methods also provide the development teams with more autonomy.

\section{II Overcoming the talent gap}

The interviewees pointed out the great advances in technology. The major challenge is 
to find qualified people to deal with the available technology, referred to as "talent gap" in the literature (Yeoh \& Koronius, 2010; Davenport, 2014; Leeflang et al., 2014). The case shows that the challenges are not restricted to technical issues. Finding people with the desired profile is an obstacle for the expansion of the area because this profile is not simply related to technical needs, but also behavioral ones.

I think that finding people is still a challenge. It's also a challenge in other areas, not only for data science. The programmer (spite), for example, is also something that's rather hard to find, a good programmer. I think that the professional is still the greatest challenge. (I8)

Next year we are going to double our size, it has already been approved. But one of the major problems with growing is finding the right people. (I2)

Given the difficulty to hire people with the desired profile, expanding the knowledge of the existing teams has been quite relevant.

Today they call us Big Data specialists, but we got here knowing nothing. I got here without any knowledge. (I8)

The acquisition of external competencies has been an alternative.

Today we have some other algorithms released, but we are not using them yet. They are algorithms from the academic area, from techniques better developed in the academy along time, and that other companies like Netflix and LinkedIn are already using a lot. (I8)

Regarding the building of a team, we propose:

P10: Qualification of internal working teams and acquisition of external competencies are alternatives to minimize the talent gap.

Given the difficulty in finding people with the desired technical and behavioral profile, qualification of internal working teams and acquisition of external competencies, such as consultants, are alternatives to overcome hiring difficulties.

\subsection{Privacy management}

The integration of available data poses ethical and legal challenges, as well as internal procedures ones.

I believe so. We need to evaluate what kind of information we may use. For example, today we have an in-company financing operation, and it's a joint venture with Magazine Luiza. So, we own half of this operation. But it's a financial institution that goes through several information compliances and they have data available right there, but I can't use it because of the compliances with the bank. (I5)

Among the ethical issues, consumer privacy management is a challenge for virtual retailers (Minelli et al., 2013; Simon, 2013; Wigan \& Clarke, 2013; George et al., 2014).

There is a risk dealing with data, information confidentiality. In the US this has been more debated, in Brazil it's just starting to be debated. So, we always try not to be invasive, mainly in the communication. (I5)

Regarding the privacy of data, we propose:

P11: The privacy of personal data is a factor to be managed in the adoption of Big Data.

The existence of sensitive data within the systems establishes the need for privacy management. Companies storing the data have the ethical and legal responsibility to preserve privacy. 


\section{I3 Technical challenges in the analyzed case}

A technical challenge concerns the storage of large volumes of data, without the risk of losing them. Another issue is related to avoiding the loss of data along the process when dealing with independent systems.

We found a super cool way of storing it, which is the graph format. Back to a simple example... I am able to know very, very quickly who your friends are, what they have bought, what has been recommended for them, what they've clicked on, how many e-mails I have sent (I2).

Another challenge is to regain insight and information with proper timing. An area where Big Data holds a major potential is data analysis in real time. The intention of Magazine Luiza is that analytics generate immediate recommendations. Speed is still a problem, though. In some occasions, the response time to the question remains slower than expected. In others, it was overcome by reducing the data to be analyzed.

One problem that exists today is response time. You put money on something, but you can't see there, on the spot, what's performing better. There is a gap. With the use of Big Data, it's becoming faster, they will be able to create a dashboard and check what is going well at the time, and get immediate return on a certain investment. (I3)

\section{Conclusion}

The objective of this research was to identify opportunities and obstacles to the implementation of Big Data in Brazilian virtual retailing through a case study on Magazine Luiza, a leading company in the use of Big Data tools for customer relationship management. The use of Big Data in the case study focused on the improvement of its recommendations system, a better understanding of consumer behavior and strategic direction. The adoption of Big Data is part of a strategic transformation process, from a traditional retailer aiming to become a dataoriented company.

As did other implementations of this nature, this project was born in the IT area, but had the involvement of the top management that later created a Technology and Innovation lab, with the purpose to create products and services with a focus on retail - Luizalabs. This happened as the results of Big Data projects started to show up. The developers of this lab are dedicated to innovation and don't deal, therefore, with the company's routine. The review of the organizational structure, mainly in the IT area, in order to adjust and expand capacity, was an aspect that favored Big Data development.

Contrary to the literature, which suggests that IT projects should seek alignment with organizational processes (Yeoh \& Koronius, 2010; Ohlhorst, 2013; Novo \& Neves, 2013; Kim et al., 2014), the implementation of Big Data at Magazine Luiza was not restricted to these processes. The cultural change from a traditional retailer to a digital company required paradigm shifts. The solutions proposed by Big Data aimed a performance improvement, looking for innovation in the company's modus operandis. This transformation generated a natural resistance, later overcome by the visible results and the integration between the IT and business teams.

Information sharing, one of the potential benefits of Big Data (Yeoh \& Koronius, 2010; Ohlhorst, 2013; Novo \& Neves, 2013; Kim et al., 2014), faced a few challenges. The physical stores often refrain from providing data to the virtual channel, perceiving it as competition. Conflicts resolution between channels needs to be addressed. Nevertheless, the data silos were broken down at the corporate level when people started to realize the returns from sharing. Resistance started to break with the trust gained from the business areas, enabling the IT and business areas to work in a more integrated manner. 
The constant management of the business areas' expectations is necessary because demands for solutions increase when they perceive Big Data's usefulness. Managing the demands and showing the users what is possible is also a need.

As the literature suggests (Ansarinejad et al., 2011), the adoption of the project management agile method has also facilitated the implementation of Big Data projects at Magazine Luiza due to the more flexible scope and the autonomy it provides to the teams.

Another frequent challenge is the talent gap which is not restricted to the technical profile, but also to behavioral aspects, mainly regarding entrepreneurship, curiosity and desire to learn. In order to deal with this reality, the teams are trained internally and also count with the acquisition of external competencies, such as consultants. Considering the difficulties with hiring people with the desired profile, improving company teams' knowledge has become very relevant.

Finally, consumer privacy management is a challenge for virtual retailers, something that can be minimized by keeping data anonymity and a proper policy on information management.

Considering the results presented, we outlined some propositions related to opportunities and obstacles to the implementation of Big Data by virtual retailers in Brazil. Some of the propositions are aligned with existing literature debates, mainly regarding BI. Nonetheless, they still need to be debated in the context of Big Data. The propositions regard the alignment of Big Data projects with the organizational strategy, the involvement of top management, the challenges related to information sharing between organizational silos, the importance of communication, the use of agile methods for projects development, overcoming the talent gap, and privacy management (P1, P2, P4, P5, P9, P10 and P11).

The main contribution of this study is related to the opportunities and obstacles it brought up, which seem to be specific to the context of Big Data, and were not yet properly addressed by the literature. These are related to the establishment of innovative processes, users' expectations management, experimentation culture, and the review of organizational structure (P3, P6, P7 and P8).

The limitations of the study are a result of the exploratory research method, with a single case study of one specific sector - virtual retail. The results can't for this reason be generalized, yet they set a base for future investigations which may use the propositions suggested to study the implementation of Big Data in different organizations and sectors.

\section{References}

Ansarinejad, A., Amalnick, M.-S., Ghadamyari, M., Ansarinejad, S., \& Hatami-Shirkouhi, L. (2011). Evaluating the critical success factors in ERP implementation using fuzzy AHP approach. International Journal of Academic Research, 3(1), 65-80.

Bingi, P., Sharma, M. K., \& Godla, J. K. (1999). Critical issues affecting an ERP implementation. Information Systems Management, 16(3), 7-14.

Bruce, W., Lenita, D., \& Paul, D. B. (2013). Perspectives on big data. Journal of Marketing Analytics, 1(4), 187-201.

Burton, R. M., Mastrangelo, D., \& Salvador, F. (2014). Introduction. Journal of Organizational Design, 3(1), 1.

Castro, S. (2014). Optimizing your data management for big data. Journal of Direct, Data and Digital Marketing Practice, 16(1), 15-18.

Chen, H., Chiang, R. H. L., \& Storey, V. C. (2012). Business intelligence and analytics: From big data to big impact. Mis Quarterly, 36(4), 1-22.

Davenport, T. (2014). Big data at work: Dispelling the myths, uncovering the opportunities. Boston: Harvard Business Press. 
Davenport, T., Barth, P., \& Bean, R. (2012). How 'Big data' is different. MIT Sloan Management Review, 54(1), 43-46.

E-Bit. (2015). Relatório Webshoppers, $31^{\circ}$ ediçâo. Retrieved from http://www.ebit.com.br/ webshoppers

George, G., Hass, M., \& Pentland, A. S. (2014). Big data and management. Academy of Management Journal, 57(2), 321-326.

Gupta, R., Gupta, S., \& Singhal, A. (2014). Big data: An overview. International Journal of Computer Trends and Technology, 9(5), 1-3.

International Data Corporation. (2014). Predictions Brazil 2014: Top trends presentation. Retrieved from http://www.brasscom.org.br/ brasscom/Portugues/download.php?cod=567

Kim, G.-H., Trimi, S., \& Chung, J.-H. (2014). Big data applications in the government sector. Communications of the ACM, 57(3), 78-85.

Leeflang, P. S. H., Verhoef, P. C., Dahlström, P., \& Freundt, T. (2014). Challenges and solutions for marketing in a digital era. European Management Journal, 32(1), 1-12.

Maçada, A. C. G., \& Canary, V. P. (2014). A tomada de decisão no contexto do big data: Estudo de caso único. Anais do Encontro Nacional da Associação Nacional de Pós-Graduação e Pesquisa em Administração. Rio de Janeiro, RJ, Brasil, 38.

McAfee, A., \& Brynjolfsson, E. (2012). Big data: The management revolution. Harvard Business Review, 90(10), 60-68.

Magazine Luiza. (2016). Quem somos. Retrieved from http://www.magazineluiza.com.br/quemsomos/multicanais/.

Minelli, M., Chambers, M., \& Dhiraj, A. (2013). Big data big analytics: Emerging business intelligence and analytic trends for today's businesses. Hoboken: John Wiley \& Sons.
Novo, R., \& Neves, J. M. S. D. (2013). Inovação na inteligência analítica por meio do Big data: característica de diferenciação da abordagem tradicional. Workshop de Pós-Graduação e Pesquisa do Centro Paula Souza. São Paulo, SP, Brasil, 8. p. 32-44.

Ohlhorst, F. (2013). Big data analytics: Turning big data into big money. Hoboken, N.J.: John Wiley \& Sons.

Schmarzo, B. (2013). Big data: Understanding how data powers big business. Indianapolis, IN: John Wiley \& Sons.

Shmueli, G., \& Koppius, O. R. (2011). Predictive analytics in information systems research. MIS Quarterly, 35(3), 553-572.

Silva, I. M. D., \& Campos, F. C. D. (2014). New perspectives using big data: A study of bibliometric 2000-2012. Proceedings of the International Conference on Information Systems and Technology Management - CONTECSI. São Paulo, Brasil 11.

Simon, P. (2013). Too big to ignore. Hoboken: John Wiley \& Sons.

Somers, T. M., Nelson, K., \& Ragowsky, A. (2001). Enterprise resource planning (ERP) for the next millennium: development of an integrative framework and implications for research. Proceedings of the Americas Conference on Information Systems - AMCIS. New York, EUA.

Sumner, M. (1999). Critical success factors in enterprise wide information management systems projects. Proceedings of the Americas Conference on Information Systems - AMCIS. New York, EUA.

Wigan, M. R., \& Clarke, R. (2013). Big data’s big unintended consequences. Computer, 46(6), 46-53.

Yeoh, W., \& Koronius, A. (2010). Critical success factors for business intelligence systems. Journal of Computer Information Systems, 50(3), 23-32. 


\section{About the authors:}

1. Bruno Muniz Félix, MSc in management, Universidade Federal do Rio de Janeiro, Coppead Graduate School of Business, Rio de Janeiro, Brazil. E-mail: bmunizfelix@gmail.com

\section{ORCID}

(iD) 0000-0003-1925-5639

2. Elaine Tavares, Ph.D in management, Fundação Getúlio Vargas, Brazilian School of Public and Business Administration. E-mail:

elaine.tavares@coppead.ufrj.br

ORCID

(iD) 0000-0002-1107-2101

3. Ney Wagner Freitas Cavalcante, Ph.D candidate in management, Universidade Federal do Rio de Janeiro, Coppead Graduate School of Business, Rio de Janeiro, Brazil. E-mail: ney.cavalcante@coppead.ufrj.br ORCID

(iD) 0000-0002-5975-2077

\section{Contribution of each author:}

\begin{tabular}{|c|c|c|c|}
\hline Contribution & Bruno Muniz Félix & $\begin{array}{c}\text { Elaine Maria } \\
\text { Tavares Rodrigues }\end{array}$ & $\begin{array}{l}\text { Ney Wagner Freitas } \\
\text { Cavalcante }\end{array}$ \\
\hline 1. Definition of research problem & $\sqrt{ }$ & $\sqrt{ }$ & \\
\hline $\begin{array}{l}\text { 2. Development of hypotheses or research questions } \\
\text { (empirical studies) }\end{array}$ & $\sqrt{ }$ & $\sqrt{ }$ & \\
\hline 3. Development of theoretical propositions (theoretical work) & $\sqrt{ }$ & & $\sqrt{ }$ \\
\hline 4. Theoretical foundation / Literature review & $\sqrt{ }$ & $\sqrt{ }$ & $\sqrt{ }$ \\
\hline 5. Definition of methodological procedures & $\sqrt{ }$ & $\sqrt{ }$ & \\
\hline 6. Data collection & $\sqrt{ }$ & & \\
\hline 7. Statistical analysis & - & - & - \\
\hline 8. Analysis and interpretation of data & $\sqrt{ }$ & $\sqrt{ }$ & $\sqrt{ }$ \\
\hline 9. Critical revision of the manuscript & & $\sqrt{ }$ & $\sqrt{ }$ \\
\hline 10. Manuscript writing & $\sqrt{ }$ & $\sqrt{ }$ & $\sqrt{ }$ \\
\hline
\end{tabular}

